\title{
1. Getting the basics right: finding the right research question
}

\section{Zsolt Nyiri}

My approach to the teaching of methodology for students of political science has been informed by my personal experiences with research methods in various settings: as a student who took many such courses at different universities, both at the undergraduate and graduate level, as a researcher of comparative public opinion, and as a practitioner who conducted, presented, and explained large-scale, multi-national surveys in the US, Europe and Asia. While most of my own research likely falls within the quantitative research label, I do not believe in the often artificially-set boundary between quantitative and qualitative methodologies. Instead, I see both approaches as essential and often complementary research tools. It is hard to imagine successful quantitative research without conducting focus-groups, expert interviews, or case studies.

Research projects, especially if travel, field study, interviews, or complicated data-collection is involved, are expensive and time consuming. Once that data is in, most of the research budget has already been spent. It is rare to go back to the field and reorient the research, add an extra question, ask the same question in a different way, or even simply change the order of survey questions. With time, the research process becomes more and more linear and irreversible. This should compel us to spend more time and intellectual energy at the front-end of the research process when things can still be easily changed. I find this to be true both in practice and teaching. Yet, surprisingly, little time is spent on the front-end of the research, even though these fundamentals will later define and dictate the entire research process. Undergraduate research method classes tend to mirror this process: students are asked early, way too early, to commit to a research question and quickly proceed to the more "challenging" technical part of the course: coding, statistics, and data analysis.

Students need adequate time to study the basics of the research process, the most basic being finding the right research question for them before they turn their attention to statistics. The extra time spent on finding the right research question for the students will pay off later as it will better plan for the rest of the research process. Moreover, by not turning to statistics too early, students' 
mathematics-anxiety can be reduced and thus we can address this important source of fear leading students away from methodology classes.

Based on my own experience as a student and an educator, I realized that most students commit to a research topic for their seminar paper hastily, too early, and without much deep thinking about the actual concepts, potential hypothesis, units of analysis, and the methodology needed to pursue that question. This will eventually lead to confusion, frustration, loss of interest in the topic, and ultimately to shoddy research because it was not planned out well. Students rarely feel comfortable changing their research topic well into the semester when they have already spent a considerable amount of time conducting their literature review, even if they concluded that this is really not so interesting for them any more. Throughout my years as a professor, I have had many of my students setting up appointments "to talk about their research" but instead of discussing their progress, they really just reveal that they've lost interest in their original research question and they are frustrated. When I ask them "OK, so let's change or modify your question" they invariably say with surprise "Am I allowed to do that?"

As a result of listening to my students' concerns, I changed my course design to spend a lot more time, at least half of the regular semester, to allow students to find and explore the right question for them. When implemented, this slow approach proved not to be wasted time; instead, it accelerated the second half of the semester: finding the right method (be it qualitative or quantitative), exploring available data sets, creating new data, finding relevant experts, and conducting statistical analysis on their data.

\section{SARTORI'S HALF-CENTURY-OLD OBSERVATION}

It seems that the practice of teaching statistics disguised as research methods in the undergraduate classroom stems from a similar practice in our field. The late Italian political scientist Giovanni Sartori is well known to researchers of parties, comparative politics, and beyond. In 1970, before most of our students and many of us in the faculty were even born, he published an article in the American Political Science Review, the official journal of the American Political Science Association. Barely into the first page of his article, Sartori wrote:

Most of the literature introduced by the title "Methods" (in the social, behavioral or political sciences) actually deals with survey techniques and social statistics, and has little if anything to share with the crucial concern of "methodology," which is a concern with the logical structure and procedure of scientific enquiry. (Sartori 1970, p. 1033) 
This astute insight into the discipline of social science from five decades ago couldn't be more relevant today, both to the field of political science and the teaching of it.

When I am reflecting on my own experience with studying methodology, I found many professors were as quick as they could be to turn the methodology course into a class on statistics, mathematical proofs, sampling, data analysis, and data presentation. The reality is that teaching research methodology, which Sartori defines above as the "logical structure and procedure of scientific enquiry" or more broadly "thinking about thinking" (Sartori 1970, p. 1033) is not to be confused with a crash course on statistics or survey methodology. Methodology is more than learning a "technique". Instead, it is the conscious exploration of a meaningful research question, clarifying the concepts involved, building a theory, and planning the entire research architecture logically that will best fit our research question.

Others also pointed out the lack of attention to some of the most basic issues of research design. Barbara Geddes (2003) eloquently quotes Percy Bysshe Shelley's "Ozymandias" in her seminal work Paradigms and Sand Castles:

The point of departure for this book is that we have made our own fate through our inattention to basic issues of research design. To be successful, social science must steer a careful course between the Scylla of lovely but untested theory and Charybdis, the maelstrom of information unstructured by theory. (Geddes 2003, p. 4)

Nothing is more basic in the research process than the question itself that we choose to study. Designing and executing political science research can be difficult and messy for many external and internal reasons, but it is guaranteed to be so if there is no well-formulated research question on which to build the research itself.

Finding the right question to study for each individual student is timeconsuming. The question needs to fit the student's deep passion for politics as well as to fit the body of knowledge that has been accumulated by previous researchers on that topic. Overemphasizing statistics or the newest statistical software at the undergraduate level will not only discourage many of our students from engaging in further scholarly study of politics but will also be a "poor and incomplete" substitute for scientific research in general (Hill 2002, pp. 114-15). 


\section{THE QUESTION AND PASSION-LED APPROACH TO RESEARCH}

With every incoming cohort of political science majors, I find myself facing the same challenge as an educator. On the one hand, I have hardly ever met a political science major who was not interested and passionate about some political issue. On the other hand, passion or interest alone do not necessarily lead to great research. With different cohorts, my role remains the same: how to turn my students' passion for politics into original, interesting, and well-designed research projects.

In my methods and substantive classes, I advocate a two-pronged approach to research: question- and passion-led research process. I like to discover, capture, and maintain the passion that students have for a certain political question throughout the semester. I urge my students to find topics that are meaningful and relevant to them, questions that look to answer real-world political problems and that can potentially improve the lives of many.

What is often covered as methods is little more than "technique" such as measurement, data, and statistical analysis. Technique is very important but should only come into play once students have a well-articulated idea about what issues they consider important personally. So why is passion important? We don't grade papers based on passion, for sure. However, passion affects everything: it's a source of mental resource and energy during the lonely hours of research. Let us be honest: a lot of the research process itself is tedious, slow, and has few initial rewards. It is the passion for the topic and the big picture problem to be addressed that will lead the student and provide enthusiasm and strength to read through a countless number of articles, some interesting, some less so, some well-written, others hard to decipher. It takes a lot of devotion to a cause to write and re-write various drafts of a paper. It's hard to do excellent research if it is only motivated by getting a good grade or improving one's grade point average (GPA). There must be some internal reward, a reward that satisfies the student's own curiosity about the world.

I came to realize the role of passion in research early on in graduate school as one of my first publications was written for a class on a topic that I was deeply passionate about but was graded relatively poorly by the professor. For this paper, I did a lot of research, interviewed many people, traveled abroad, and spent a lot of time alone writing and re-writing various drafts. While the paper was not rewarded with an A, the passion for the research question kept me working even more on the paper, beyond the class, into the summer break. This research happened to lead to one of my first publications in a peer-reviewed journal. Had I not had passion for the topic and commitment to study what 
I thought was a crucial problem in politics at the time, I am sure I would not have pursued a paper that received a less than perfect grade.

\section{WHAT IS A "GOOD QUESTION" AND HOW TO FIND ONE?}

Following the principle of passion and question-led research should not just be a pedagogical approach in an undergraduate methods class but a lifetime commitment for all scholars. We find ourselves way too often pursuing research projects that are not led by passionate questioning of real-life problems but, rather, simply because they match the techniques with which we are already familiar. While this is often a successful way to becoming a productive scholar, it might also lead to burnout as a human. I often have to remind myself not to become a data- or methods-led researcher (the opposite of question- and passion-led researcher), who can easily locate new and interesting data and work my way backwards to a research question.

Finding the "right question" will be different for each student and for each class. This is the most personal and least mechanical part of the research process. It needs creativity from the student and a great deal of personal attention to the student by the professor. In their classic methodology textbook, Gary King et al. (1994) note:

The rules of choice at the earliest stages of the research process are less formalized than are the rules for other research activities. There are texts on designing laboratory experiments on social choice, statistical criteria on drawing a sample for a survey of attitudes on public policy, and manuals on conducting participant observation of a bureaucratic office. But there is no rule for choosing which research project to conduct... (p. 14)

How do we encourage undergraduate students to be passionate, investigative, and focus on political questions that matter? In my classes, I advise students to develop a research identity throughout the semester: find a broad topic area or a country or a region that they personally find important, relevant, and perplexing. Whether it is a methodology class or some other, topical, class, I start the semester inquiring about what my students consider to be the biggest political problem we face as a country. I recommend this to be the part of the first class as students introduce themselves. This process helps as an ice-breaker, a conversation starter, and it reveals a lot about the motivation of our students to enroll in a political science class. This is also a great way for the professor to better understand our students' lived experience and keep in touch with how younger generations think about politics. 


\section{THE ROLE OF CONTROVERSIAL POLITICAL ISSUES IN FINDING RESEARCH QUESTIONS}

While most political topics are inherently contentious and this is exactly why they become political, I can also understand why some professors might avoid such topics for the sake of peace in the classroom and to reduce stress levels of students. However, I do find that most students who enroll in political science courses do that to learn more about such controversial topics. I consider this an advantage and I believe if it is done with attention and care - focusing on the scientific study of such political issues - current and controversial political issues are an immense treasure of research questions that students deeply care about. Hence, I advise not to shy away from controversial topics in the political science classroom for two main reasons: (1) because students tend to have passionate opinions about those, and (2) because many of them can be formed into excellent research questions for further exploration. Once again, this can only be done when the professor is able to create a trusting environment and lead the discussions on such topics so that they are productive and scientific as much as they are relevant.

The passion for politics among our students is there, perhaps more than ever in recent history. Various surveys reveal that the most recent wave of American politics, with charismatic and controversial national leaders such as Barack Obama and Donald Trump, has made young people more interested in politics than before (Holbein 2020). In 2016, an astoundingly high number, nine out of ten (90 percent) of young Americans between the ages of 18 and 29 , expressed that they were interested in politics, and eight in ten ( 80 percent) intended to vote (Holbein and Hillygus 2020; Holbein 2020). While the number of younger people who actually participate in elections does not match up to these high numbers, there is clearly a lot of interest in politics among young people. If only political science professors could turn this interest into more political participation, more political research, and, of course, higher enrollment numbers in methodology courses!

Increased interest comes with a price: many of our students are directly hurt by current political issues, such as racial discrimination, police brutality, LGBTQ rights, joblessness, an expensive health care system, and the general polarization of Americans. How do we turn controversial, provocative, and often painful political questions into great research questions? Let's look at one example: in 2018, major news sources reported that behind closed doors, Donald J. Trump, the President of the United States of America, labeled the home countries of many immigrants as "sh-thole" countries, referring to immigrants from Haiti and African nations (Dawsey 2018; Vitali et al. 2018; Watkins and Phillip 2018). While the President denied using the actual word 
quoted above, he did admit to using "tough language" (O'Keefe and Gearan 2018). Is there a place in a classroom to discuss such a distasteful alleged statement? If stripped down, does the President have a point as to the larger trends of international immigration to the US?

There is no doubt that the language that was used to describe a group of countries is unacceptable and has no place in politics, even beyond closed doors, or in a classroom. This needs to be communicated to students with clarity. But the statement itself relates to some very real political issues that are worth further study. A more scientific look at those issues could lead to excellent research questions such as:

- Are people from poorer countries more likely to migrate to the US than people from wealthier countries?

- Do Americans have different attitudes towards immigrants from Africa when compared to immigrants from Europe?

- What is the best way to measure international development?

- Do politicians tend to describe the countries of Africa in more negative terms compared with other continents?

- Are immigrants from Africa less likely to contribute to the US economy than immigrants from other continents?

These questions above are all excellent and appropriate for serious research in an undergraduate class and beyond. They are relevant to current politics and students will likely be able to relate to them. There is ample academic literature related to any of these questions. The papers on such topics will no doubt enlighten students in any political science class. With the increasing polarization of American politics, one can expect that the number of controversial statements about political phenomena reported by the media will continue to rise. Many of the questions surrounding these controversial statements do touch students' personal lives, or resonate with them, and can lead to very real scientific investigations in methods classes.

\section{QUESTIONS THAT FIT THE DISCIPLINE}

Students most often bring their passion for political questions from experiences in their private lives, their communities, or following the media. But passion about politics is rarely enough for a successful research paper. Research questions need to fit into the larger context of available literature, use or extend concepts that have been tried by others, and so on. Research methods classes often require students to conduct literature reviews after they have already committed themselves to a research question. However, a thorough literature review can easily change a student's willingness to conduct further research 
on their chosen question. Students might find that their research question is not original at all and they have already been addressed by others. They might find that answering their original questions will need a lot more time and resources than they were expecting.

In my experience, it is helpful for students to conduct literature reviews at the same time as they are perfecting their research question and not after they have already committed to it. This, of course, is time consuming but it will allow students to specify, alter, or entirely abandon a question and find a new one if necessary. The one-semester research methods class rarely allows for time for slow and thorough research question development accompanied by literature review. Rushing to an early declaration of research questions without understanding the state of the discipline will force many students to stick to their original question even if they have lost interest. In order to overcome this, I recommend a parallel process of choosing a tentative research question or identifying a political problem, conducting a literature review, and revising and perfecting the research question while doing this.

Keeping research questions grounded in the discipline is crucial and this leads to one of the most important components of finalizing a research question: a thorough understanding of what others have already found on that topic, that is, a literature review. Kuhn's observation from 1970 still holds true that "[o]nly very occasionally ... do facts collected with so little guidance from pre-established theory speak with sufficient clarity ..." (Kuhn 1970, p. 16). Contribution to the larger body of research can be of different types: a causal explanation of a political phenomenon, an explanatory case study, a new and better measurement of a complex concept or variable, among many others.

\section{THE ROLE OF THE LITERATURE REVIEW IN PERFECTING THE RESEARCH QUESTION}

It's discouraging to see that many real-life political problems, from race and police shootings to equal pay, are closely studied by social science researchers but their findings are not readily available for the public nor are they discussed by politicians. Accordingly, most of our undergraduate students who are deeply interested in political issues find it difficult to name even one nationally known political scientist. Throughout the semester, I find that many of my students are quite surprised by the amount of policy-relevant research already available but virtually unknown to the public.

For example, it was reported in the American media that President Trump was genuinely surprised by why the US would not use its nuclear weapons (Belvedere 2016). While this might be a genuinely honest question (why build something if we don't intend to use it?), any introductory level course on international relations would surely cover the answer: mutual deterrence. 
However, political science does not always produce clear-cut answers to political problems. Many findings of political science research are complex and often contradictory. A thorough literature review can leave students disappointed by not presenting clear-cut answers to the questions they study. Barbara Geddes (2003) warns that most literature only establishes a very "fuzzy research frontier" when she writes: "The literature on some subjects contains only a few arguments generally accepted as true; many controversies in which the hypotheses on both sides lack both clarity and strong empirical support; and large amounts of opinion and conjecture, unsupported by systematic evidence but nevertheless often referred to as theory" (p. 29).

The confusing time of literature review is also the time when many students will inevitably change their original research question. Some will see this as a defeat, that they picked the "wrong question". Professors should find the time to explain that it is not uncommon to change research questions well into the research process, even for seasoned researchers.

A literature review can reveal that some research questions have already been answered but that doesn't mean a question should be completely abandoned. I encourage these students to explore further the state of the art and see if they are willing to push the current standing of research on their topic: is there new evidence that might suggest earlier findings do not hold? Can we add another strong case to support the original argument? There are many options to guide the students through the "solved problem" roadblock. Some of my students are stimulated by the lack of clear findings on their research question and that will energize their research effort to find out who is right.

Is the frequent lack of scientific consensus in the political science literature a weakness of our field? It sure does not help but it also makes political science intriguing. The "fuzziness" doesn't make political science a lesser science than hard sciences. Rather, this reflects the fact that we study the constantly changing, messy world of real politics, not atoms or chemical agents in a laboratory setting. The fuzzy nature of our research is also our strong point: in political science, we study real, complex, ever changing, and highly impactful issues. And ultimately, our deep interest in the real world will make us good researchers.

\section{TESTING RESEARCH QUESTIONS THROUGH IN-CLASS PEER REVIEW}

A good research question is not just interesting to the individual who crafted it but also to others. I urge students to ask themselves: Can I convince others that my research is interesting and important? What will happen if I find out the answer to my question? From an early stage in my methodology class, I foster an academic community among the students: students are requested to 
update the class on their research regularly, and they are required to work as peer-reviewers of each other's drafts, for example. I find students generally to be excellent at vetting each other's ideas. Even if they are not experts, they are very honest at revealing whether they find a particular question interesting, relevant, and non-trivial, and if the reasoning behind a hypothesis is convincing or not. I also steer students to think about the potential effects of their research on society: is finding out the answer to a question likely to change the world in a positive way, leading to the betterment of life for us and others? The Craft of Political Research by W. Phillips Shively (1990) is an excellent example of such an approach in detailing how ideas produce research questions and guide the selection of research methods.

\section{QUESTIONS GREAT AND SMALL}

Big picture political science topics (terrorism, race relations, immigration, etc.) are very important and are what brings most students to a political science class. They are also important to keep in mind to maintain interest in political science research. However, it is equally important that students become realistic about the piecemeal nature of political science research. This is not just an attribute of political or social sciences; the progress of science itself is mostly about the culmination of small discoveries. While keeping the big picture in mind, students need to be realistic that most research projects only add a small piece to solve a greater puzzle. There is nothing wrong with this, but the process of actual scientific discovery needs to be explained in class because it is not intuitive to many. Students are often too optimistic in their expectations with regard to the final research paper but it is hardly likely that one will solve, or even explain, world hunger, war, or terrorism in one undergraduate research paper.

In my experience, most students quickly accept the piecemeal nature of scientific progress. While, as Charles Tilly (1984) puts it, we are seeking "big structures, large processes, huge comparisons", we will most likely end up making small discoveries. Still, following big dreams such as solving world hunger can become a student's future research path and a lifelong commitment to a topic, through several smaller projects. Barbara Geddes also points out that there is no inherent contradiction between thinking big and small as she writes "big, romantic, untestable ideas can be made amenable to rigorous investigation by first breaking them up into their component processes" (Geddes 2003, p. 40). 


\section{QUESTIONS THAT CAN BE MEASURED AND ANSWERED}

A research question is only good to the degree it can be answered via the empirical method through observation. Observations can be based on surveys, focus groups, interviewing experts and policy-makers, compiling pertinent case studies, and so on. I constantly remind my students in search of their research question to think about "How will I know the answer to my question?" This is why finding the right question is so important: it informs and directs the researcher for the rest of the research process, including finding the appropriate "technique".

By the time students refine their research questions into a hypothesis through various peer-reviews and by consulting the relevant literature, they must be very specific regarding the concepts and variables being studied. Here, students face two crucial questions:

1. Are there reliable and valid measures already available for me to use in testing my hypothesis?

2. Do I need to create new or improved measures that are available to answer my research question?

When there are no data available to test a hypothesis, I encourage students to create a better measurement than what's available and collect the data if that is feasible. Focus groups and interviews are often appropriate in lieu of representative surveys for this exploration.

\section{TURNING A QUESTION INTO A RESEARCH HYPOTHESIS}

Once students identify their research questions, the next challenge is to turn that question into a propositional statement, a hypothesis. Framing the hypothesis is more formalized and less intuitive than finding the right question, but not without potential pitfalls. At this point, students are already expected to think of the future research steps: levels of analysis, variables (dependent and independent), measurements, positive or negative relationships, and so on. Ultimately, all scientific hypotheses are organized in a very similar fashion. For political science undergraduates, Philip H. Pollock (2015) provides an excellent template for hypothesis writing that I found very helpful in my own teaching - with linguistic alteration of the language for each specific case to make it more reader-friendly: "In a comparison of [units of analysis], those having [one value on the independent variable] will be more likely to have 
[one value on the dependent variable] than will those having [a different value on the independent variable]" (Pollock 2015, p. 54).

If done with care, which needs time, by the time students have built a clear and focused research question, the entire research process should be on the right track. With a solid research question the accompanying hypothesis is halfway to a successful research paper. It shows evidence that students have seriously thought about the relevance of their question, were able to identify and delve into relevant literature, and are familiar with the theory and concepts being involved, major discoveries, and gaps in the study of this topic within the political science literature. By now, students are expected to lay out even more tangible research components: what kind of data they will need for their hypotheses, what are the likely causal relations, what statistical tests and mathematical models to use, among others.

\section{LEADING BY EXAMPLE}

It is well documented that many students are afraid of taking a class in research methods (Adriaensen et al. 2014; Bernstein and Allen 2013; Buchler 2009; Hill 2002; Oldmixon 2018). And, truthfully, equally afraid are many faculty members assigned to teach these classes, for different reasons of course. In my experience, openness and honesty go a long way in a methods class. Research methodology is indeed complicated and/or dreary, often even for the seasoned researcher: the language tends to be too technical, coding is boring, and mathematics can be confusing for social scientists. Sharing our own ways of handling the difficulties of the research process, including our own search for the right research question, tends to help to relate to students and manage their anxieties.

In my own experience, presenting a realistic picture of the research process, with its ups and downs, proved to be very rewarding. Instead of scaring students away from doing their research, it made the whole process more relatable. As a best practice, I recommend setting aside an entire class period to presenting one of our own papers in great detail, including the emotions we went through during the writing and research. As researchers, we are accustomed to displaying our research in a well-rehearsed, well-organized, and neatly packaged 10-15-minute-long presentation with visual aids. During these presentations we focus on what went well during the research. A suave and polished presentation at a conference is very much desired. However, a similar presentation in a methods class will make students feel that research is much easier than they themselves are experiencing. But research has its own challenges for professors as well, which we usually do not like to share beyond co-authors and close friends. 
I usually start with my own motivation to study political issues and how I developed my own interest in the scientific study of politics when I lived through the collapse of communism. I explain my growing interest as an undergraduate student in comparing the experience of different countries with major social and political changes. I talk about what kind of problems I find fascinating in general but also how hard it is to work with competing research questions and agree on a specific testable research hypothesis. Speaking about concrete examples, I explain to my students that, in the case of this particular article, my original research question changed considerably throughout the research process. As a matter of fact, after analyzing the data we needed to dismiss the original hypothesis and go with an alternative hypothesis. While disappointing, the alternative hypothesis led to a new discovery that was counter-intuitive and even more fascinating than the original theory we developed. Moreover, it's never too embarrassing to talk about coding errors, flipped values in a data set, or a devastating peer review, and that the published paper is quite different from how we originally imagined it. Most importantly, I emphasize for my students that without the deep passion for the topic and the fascinating research question, this paper might have never survived the ebb and flow of the research process.

\section{CONCLUSION}

This chapter argued that undergraduate methods courses should spend more time and attention than is customary on finding and refining the right research question, the very foundation of methodology. Undergraduate methods classes are usually offered as one-semester courses and, due to time constraints, professors tend to rush the basics in order to get to the mathematically more challenging statistics part of the course material. I believe this is often the reason why students dislike methodology: not because of the scientific method itself but due to too much focus on data analysis, mathematics, and statistics. Conducting research that is passion- and question-led, instead of being driven by methodology or statistics, is less stressful for the students as mathematics-anxiety holds many students back from doing well in a methods class.

A question that is well thought out informs the entire research process, from conceptualization to data collection and analysis. Instead of rushing into statistics, professors should take their time and facilitate students' finding the right questions by exploring their deep-rooted interest in politics, looking at contentious political issues, and leaving ample time for literature reviews, in-class discussions, peer groups, and changes, if necessary. In my experience, professors can reduce methods anxiety by sharing their own experience with 
the research process in detail, not hiding the failures and disappointments they confronted.

Ideally, I would recommend a two-semester course for undergraduate research methods so that the basics of research are not rushed to give way to statistics. This is usually not realistic in most programs, which are one semester in length, but spending more time on question development is an attainable goal. A strong focus on the creative process of exploring important and relevant political issues to generate research questions as well as thinking deeply about what Sartori (1970) identified as the "logical structure and procedure of scientific enquiry" will benefit all undergraduate research method courses.

\section{REFERENCES}

Adriaensen, Johan, Evelyn Coremans and Bart Kerremans. 2014. "Overcoming Statistics Anxiety: Towards the Incorporation of Quantitative Methods in Non-methodological Courses". European Political Science 13 (3): 251-65.

Belvedere, Matthew J. 2016. "Trump Asks Why US Can't Use Nukes: MSNBC". CNBC. 3 August. Accessed at https://www.cnbc.com/2016/08/03/trump-asks-why -us-cant-use-nukes-msnbcs-joe-scarborough-reports.html.

Bernstein, Jeffrey L. and Brooke Thomas Allen. 2013. "Overcoming Methods Anxiety: Qualitative First, Quantitative Next, Frequent Feedback Along the Way”. Journal of Political Science Education 9 (1): 1-15.

Buchler, Justin. 2009. "Teaching Quantitative Methodology to the Math Averse". PS: Political Science \& Politics 42 (3): 527-30.

Dawsey, Josh. 2018. "Trump Derides Protections for Immigrants From 'Shithole' Countries". Washington Post. 12 January. Accessed at https://www.washingtonpost .com/politics/trump-attacks-protections-for-immigrants-from-shithole-countries-in -oval-office-meeting/2018/01/11/bfc0725c-f711-11e7-91af-31ac729add94_story .html.

Geddes, Barbara. 2003. Paradigms and Sand Castles: Theory Building and Research Design in Comparative Politics. Ann Arbor, MI: University of Michigan Press.

Hill, Kim Quaile. 2002. "The Lamentable State of Science Education in Political Science". PS: Political Science and Politics 35 (1): 113-16.

Holbein, John. 2020. "Why Many Young People Don't Vote - And How to Fix That". American Political Science Association. 16 March. Accessed at https:// politicalsciencenow.com/why-many-young-people-dont-vote-and-how-to-fix-that/.

Holbein, John B. and D. Sunshine Hillygus. 2020. Making Young Voters: Converting Civic Attitudes into Civic Action. Cambridge: Cambridge University Press.

King, Gary, Robert O. Keohane and Sidney Verba. 1994. Designing Social Inquiry: Scientific Inference in Qualitative Research. Princeton, NJ: Princeton University Press.

Kuhn, Thomas S. 1970. The Structure of Scientific Revolutions. 2nd edn. Chicago, IL: University of Chicago Press.

O'Keefe, Ed and Anne Gearan. 2018. "Trump, Condemned For 'Shithole' Countries Remark, Denies Comment but Acknowledges 'Tough' Language”. Washington Post. 13 January. Accessed at https://www.washingtonpost.com/politics/trump 
-acknowledges-tough-language-but-appears-to-deny-shithole-remark/2018/01/12/ c7131dae-f796-11e7-beb6-c8d48830c54d_story.html.

Oldmixon, Elizabeth A. 2018. "“It Was My Understanding That There Would Be No Math': Using Thematic Cases to Teach Undergraduate Research Methods". Journal of Political Science Education 14 (2): 249-59.

Pollock, Philip H. III. 2015. The Essentials of Political Analysis. 5th edn. Los Angeles, CA: CQ Press.

Sartori, Giovanni. 1970. "Concept Misformation in Comparative Politics". American Political Science Review 64 (4): 1033-53.

Shively, W. Phillips 1990. The Craft of Political Research. New York: Prentice-Hall.

Tilly, Charles. 1984. Big Structures, Large Processes, Huge Comparisons. New York: Russell Sage Foundation.

Vitali, Ali, Kasie Hunt and Frank Thorp. 2018. "Trump Referred to Haiti and African Nations as 'Shithole' Countries". NBC News, 11 January. Accessed at https://www .nbcnews.com/politics/white-house/trump-referred-haiti-african-countries-shithole -nations-n836946.

Watkins, Eli and Abby Phillip. 2018. "Trump Decries Immigrants From 'Shithole Countries' Coming to US”. CNN. 12 January. Accessed at https://www.cnn.com/ 2018/01/11/politics/immigrants-shithole-countries-trump/index.html. 